\title{
POBLAMIENTO INDÍGENA EN AL-ANDALUS E INDICIOS DEL PRIMER POBLAMIENTO ANDALUSÍ ${ }^{*}$
}

\author{
Manuel ACIÉN ALMANSA \\ Universidad de Málaga
}

Sobre el presente trabajo, lo primero que he de decir es que su título me fue sugerido por la organización del coloquio al que fue en su día presentado, si bien lo acepté de buen grado, no porque lo considerara idóneo con mi línea de investigación, sino porque creo que en ocasiones se hace necesario forzar esa línea e intentar abordar cuestiones nuevas, aunque éstas sean más dificultosas. Esta afirmación se refiere a la totalidad del título, y en consecuencia he aceptado también lo de uindicios" del primer poblamiento andalusí, pues con tal expresión me imagino que se refieren a la propuesta que formulé hace algunos años sobre uno de los tipos de asentamientos islámicos de primera época, puesto que, salvo eso, si bien es verdad que vengo centrando mi investigación en el período del Emirato, también es cierto que a partir de la práctica arqueológica resulta dificilísimo datar y reconocer elementos anteriores al s. IX, cuando el reconocimiento de los de ese último siglo citado ha sido un hecho recentísimo'.

Aun así, trataré de centrarme en los aspectos poblacionales del s. VIII, para el cual se nos convoca, utilizando para ello los escasos datos arqueológicos con que contamos, más los que proporcionan las fuentes escritas y la toponimia. Otras limitaciones de principio son, por una parte, la geográfica, ya que me limitaré a la

\footnotetext{
* El texto que ahora se publica fue presentado al coloquio El siglo VIII. Islam y Occidente, un primer encuentro, organizado por la Universidad de Alcalá de Henares, la Casa de Velázquez y el Instituto de Cooperación con el Mundo Árabe, que tuvo lugar en Alcalá de Henares y Madrid, entre los días 31 de marzo y 3 de abril de 1993. Pese al tiempo transcurrido, he mantenido la totalidad del escrito (incluido el título que, como se explica en las primeras líneas, me fue sugerido por la organización), del que tan sólo se han corregido algunas citas que figuraban en prensa, pues tampoco se ha publicado mucho sobre el poblamiento del siglo octavo. Algunos datos que incluyo sobre la conquista, ahora se pueden seguir más cómodamente en P. Chalmeta, Invasión e islamización. La sumisión de Hispania y la formación de al-Andalus, Madrid, 1994, mientras que sí han aparecido dos excelentes trabajos sobre el poblamiento durante el emirato, el de Sonia Gutiérrez que se cita en la nota 23, y el de Juan Carlos Castillo Armenteros, La Campiña de Jaén en época emiral ( $s$. VIII-X), Jaén, 1998, que pese a su valor no invalidan lo que se decía en la comunicación. Sí se puede completar ésta con otro trabajo mío que se acaba de publicar, «El final de los elementos feudales en al-Andalus: fracaso del 'incastellamento' e imposición de la sociedad islámica", en M. Barceló y P. Toubert (eds.), "L'incastellamento", Actes des rencontres de Gerone, 26-27 novembre 1992 et de Rome, 5-7 mai 1994, Roma, 1998.

${ }^{1}$ Sobre ello, Acién Almansa, M., «La cultura material de época emiral en el sur de al-Andalus. Nuevas perspectivas", en Malpica Cuello, A. (ed.), La cerámica altomedieval en el sur de al-Andalus. Primer Encuentro de Arqueología y Patrimonio, Granada, 1993, 153-172.
} 
zona sur de al-Andalus, y preferentemente a la actual Andalucía Oriental, aunque sin rechazar excelentes ejemplos de otras áreas, y, por otra parte, y como consecuencia de las anteriores limitaciones, las alusiones a la población conquistadora se referirán de forma casi exclusiva a los grupos árabes, lo que obedece a la única razón de que son más fácilmente detectables en la zona y cronología propuestas.

Una vez hechas esas observaciones, se ha de indicar que la antigua hipótesis sobre los primeros asentamientos islámicos en la Península, que a un nivel general vinculaba a la población árabe con las llanuras irrigadas, y a los grupos beréberes con la Meseta y las zonas montañosas, se vio matizada muy convenientemente por Pierre Guichard, indicando el poblamiento eminentemente beréber de la zona levantina ${ }^{2}$, lo cual con posterioridad se ha podido confirmar arqueológicamente con el área de dispersión de la olla de cuello alto u «olla valenciana", exclusiva para esa zona de la Península ${ }^{3}$.

De esta nueva situación resulta que las concentraciones de la población árabe en un primer momento se reducen a dos grandes núcleos, que son los valles del Guadalquivir y del Ebro o, si se quiere, los respectivos centros de la Bética y la Tarraconense. En estos dos núcleos no deja de haber asentamientos en las principales ciudades, pues si bien para el momento de la conquista tan sólo contamos con la noticia referente a Córdoba de que Mugị "repartió a sus soldados por la ciudad ${ }^{4}$, y el poco verosímil relato de al- 'Udrī sobre asentamiento de árabes durante el cerco de Huesca ${ }^{5}$, para los años inmediatamente posteriores comienzan a surgir las noticias sobre poblamiento o gobernadores en dichas ciudades; así, en la antigua Tarraconense aparecen con gobernadores árabes Gerona, Barcelona, Tortosa, Huesca, Tarazona y Zaragoza como mínimo, mientras que en la Bética el número es mayor: Sidonia, Niebla, Sevilla, Carmona, Écija, Córdoba, Mentesa, Elvira, e incluso fuera del valle, Málaga, cuya mezquita fue construida por Mu'āwiya b. Șāliḥ al-Ḥimșîn .

Este hecho es independiente de cuál fuera la realidad física de esas ciudades y también de sus posibilidades reales para articular y controlar el territorio. Pero de él se deduce una importante correción a la historiografía, como son las

\footnotetext{
2 "Le peuplement de la région de Valence aux deux premiers siècles de la domination musulmane", Mélanges de la Casa de Velázquez, V (1969), 103-158.

${ }^{3}$ Bazzana, A., "La cerámica de uso común», en Lerma, J. V., y otros, La cerámica islámica en la ciudad de Valencia (II)-Estudios, Valencia, 1990, 64, sobre esa originalidad, pese a que el autor duda de ligar a las modalidades del poblamiento medieval.

${ }^{4}$ Al-Maqqarī, Apéndice II a Ajbar Machmuâ (Colección de tradiciones), Crónica anónima del siglo XI, dada a luz por primera vez..., por D. Emilio Lafuente y Alcántara, Madrid, 1867, 183.

${ }^{5}$ Lo recoge Viguera, M. a J., Aragón musulmán, Zaragoza, 2.a ed., 1988, 39.

${ }^{6}$ Lévi-Provençal, E., La Péninsule Ibérique au Moyen Age d'après le Kitäb ar-rawḍ al-mi'tār d'Ibn 'Abd al-Mun'im al-Himyari, Leiden, 1938, 178, trad., 214.
} 
interpretaciones que se suelen dar sobre las rivalidades de los últimos wälíes de al-Andalus, Yūsuf al-Fihrī y al-Șumayl, manteniendo la versión cordobocéntrica de las fuentes, cuando en realidad de lo que se trata es de una auténtica partición del territorio, o mejor, del gobierno sobre los árabes concentrados en los dos valles, a partir de sendas capitales, Córdoba y Zaragoza.

Pero la toponimia, juntamente con la información de los textos, también ayuda a establecer otros primeros asentamientos. Antes aludía a la propuesta que realicé de considerar los qilā' y los topónimos Alcalá derivados de ellos como asentamientos de grupos árabes de un primer momento ${ }^{7}$. Me basaba para ello en su aparición en las fuentes ya como topónimos fosilizados, a lo que obedecía la anteposición del descriptivo, generalmente hịsn o madīna, según cuál hubiera sido su evolución posterior, y asimismo en la función y noticias sobre los orígenes de los topónimos Alcalá más conocidos, que se han conservado en los actuales Calatrava, Alcalá de Henares y Calatayud. Su ubicación geográfica indica claramente su función de conexión entre los dos grandes núcleos ya indicados, y en cuanto a su fundación, son de sobra conocidas las referencias a tābi 'ún que expresan lo temprano de su origen y la prosapia con que se conciben ${ }^{8}$.

Con posterioridad a ello, reflejé en un mapa de la actual Andalucía la ubicación de los topónimos Alcalá conservados hasta hoy, y pese a lo aleatorio del método, resultaba evidente su concentración a lo largo del valle del Guadalquivir, desde Alcalá de los Gazules hasta Alcalá la Real, y su práctica inexistencia en Andalucía Oriental, es decir, coincidiendo con el área de concentración de población árabe?.

Las noticias de las fuentes, además de ampliar el número de qilă en la misma zona, apoyan dicha interpretación. Así, sobre Qal 'at Yahșub, o Qal 'at Aștalīr, se nos dice que se fundó en una fecha tan temprana como el 713, y que se asentaron en ella yaḥsubíes y los descendientes de 'Ans b. Mālik' ${ }^{10}$. Con posterioridad a ello poseemos información sobre el paso de qilä a husūn, a lo que obedecen "el hisn conocido por al-Qulay'a», o el «hișn al-Qal'a» del Muqtabis $V^{11}$, posiblemente el mismo «ḥiṣn al-Qal'a» de la región de Wādī 'Abd Allāh" ${ }^{12}$, y también sobre las

\footnotetext{
7 "Poblamiento y fortificación en el sur de al-Andalus. La formación de un país de hușūn", en III Congreso de Arqueología Medieval Española. Actas. I. Ponencias, Oviedo, 1989, 140-141.

${ }^{8}$ Lévi-Provençal, E., La Péninsule Ibérique, 163, trad., 195, n. 5, y 196, n. 2. Con independencia de la presencia real o imaginaria de esos personajes, que ha analizado Marín, M., "Şahaba et täbi 'ūn dans al-Andalus: histoire et légende», Studia Islamica, LIV (1981), 5-49.

9 "Recientes estudios sobre arqueología andalusí en el sur de al-Andalus", Aragón en la Edad Media, IX (1991), 368.

${ }^{10}$ Cano Ávila, P., Alcalá la Real en los autores musulmanes, Jaén, 1990, 39.

${ }^{11}$ Al-Muqtabas (V) de Ibn Hayyān, ed. P. Chalmeta, Madrid, 1979, 161 y 164.

12 Vallvé Bermejo, J., "La división territorial en la España musulmana. La cora de Jaén", AlAndalus, 34 (1969), 72.
} 
transformaciones a que se someten algunos de ellos en época de la fitna, diciéndosenos de Dāwūd b. Sulaymān, que edificó (banà) en la kūra de Šadūna un hișn y qal' $a$ Jawlān ${ }^{13}$, lo que hay que interpretar como que edificó un hișn y modificó, de acuerdo con las necesidades de un șăhib, una antigua qal'a $a^{14}$. También Ibn Ḥayyān nos proporciona la única noticia que poseemos sobre Qal 'at Abī Ayyūb, que fue utilizada en los primeros años de 'Abd al-Raḥmān III por los mercenarios que vigilaban entre Écija y Tākurunna ${ }^{-15}$; la ausencia de noticias anteriores y posteriores parece indicar que se trata de una antigua qal'a abandonada, utilizada en ese momento por los hašam como centro de operaciones. En los Ajbär maŷmū'a se alude a una Qal 'at Tudmīn cuando los enfrentamientos entre Yūsuf al-Fihrī y 'Abd al-Raḥmān al-Dājil, que no debía ser conocida en el momento de la redacción, puesto que se especifica que estaba a una milla al Norte de Córdoba ${ }^{16}$, y algo semejante debió ocurrir con el Qal'at al-Ragwāl, pues aunque los autores árabes la citan desde el momento de la conquista ${ }^{17}$, sin embargo, la sitúan mal ${ }^{18}$. De este tipo de noticias, una de las más interesantes es la referida a las fortificaciones que lleva a cabo el emir Muhammad en Qal 'at Rabāh y Țalabīra, la primera de las cuales se expresa ya como madinna, pero, sin embargo, de la segunda no se dice que sea una qal $^{\prime} a^{19}$. O sea, que en tiempos de ese emir ya no se edifican $q i \bar{a}^{c}$, fortifica una ya existente y otra plaza nueva, que ya no recibe ese nombre.

Por los datos expuestos hasta el momento, parecen claros el sentido y la cronología propuestos, aunque reconozco que se pueden efectuar varias objeciones. De todas ellas la más real es la que se refiere a la vinculación entre qila $\bar{a}^{-}$y población árabe, pues es sabido que el centro de la región de Magīla se denominaba Qal'at al-Ward, ocupado por esos beréberes en tiempos del emir 'Abd Allāh tras ser evacuado por los árabes, y con una ubicación, en la zona de 113.

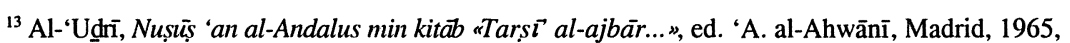

${ }^{14}$ El relato más explícito sobre la transformación de una qal'a en hiṣn es el referido a Qal'at Yaḥsub en la época de la fitna que da Ibn Ḥayyān, Al-Muqtabis, tome troisième, chronique du règne du calife umaiyade 'Abd Allah à Cordoue, texte arabe..., ed. M. M. Antuña, París, 1937, 90-91.

${ }^{15}$ Al-Muqtabas (V), 77.

${ }^{16}$ Ajbar Machmua, 93.

${ }_{17}$ Valencia, R., Sevilla musulmana hasta la caída del califato de Córdoba. Contribución a su estudio, Madrid, 1988, 235.

${ }^{18}$ Gordón Peral, M. ${ }^{2}$ D., "De la importancia de la atestiguación documental para el estudio de la toponimia. A propósito de la localización de Qal'at al-Ragwāl», Al-Qantara, XIII (1992), 356, quien piensa que sucede "por pérdida de importancian.

${ }^{19}$ Lévi-Provençal, E., La Péninsule Ibérique, 163, trad., 196, y Molina, L., Una descripción anónima de al-Andalus, Madrid, 1983, t. I, 146, trad., t. II, 156. 
Marbella, muy diferente de los anteriores ${ }^{20}$. También relacionado con población beréber, en este caso Kutāma, tenemos a Qal'at al-Ḥanaš (Alange) ${ }^{21}$, si bien, según las indicaciones del Muqtabis $V$, parece ser que estaba abandonado y lo ocuparon los Kutāma, hasta entonces establecidos en hiṣn Saktān, con ocasión de un ataque de Ordoño I $^{22}$. Igualmente, cabe la posibilidad de que los topónimos Alcalá que aparecen en la zona levantina también estén vinculados al poblamiento mayoritariamente beréber de la zona. De todas formas, resta la cronología de primera época de Qal 'at al-Ward, la posibilidad de un Qal'at al-Ḥanaš abandonado y, entre los levantinos, no se puede relacionar con población beréber el Alcalá de Mula, ni lógicamente con la población indígena, vinculada a la Mula del Pacto de Teodomiro ${ }^{23}$, por lo que su edificación se ha de entender como obra de una población nueva que se introduce en ese terreno indígena, y en este caso esa población nueva se ha de interpretar como grupos árabes. En consecuencia, no todos los qilā' se han de vincular de forma exclusiva con el poblamiento árabe, pudiendo existir también los relacionados con algunos grupos beréberes, pero aun así, el sentido para la mayoría sigue siendo el mismo.

Tampoco se puede decir, en rigor, que el término qal' $a$ se emplee de forma exclusiva para esas primeras fortificaciones, puesto que en el uso literario se dice incluso de Bobastro ${ }^{24}$, o de la propia Alhambra en época nazarí. Se usa, de manera genérica, para construcciones cristianas del otro lado de la frontera, y el mismo 'Abd al-Rạ̣mān III edificará Qal'at Jalīfa ${ }^{25}$. En unos y otros casos es claro el uso del término como sinónimo de otros con los que se alterna, como los más genéricos hușūn o ma'āqül, mientras que en la de 'Abd al-Raḥmān III es lícito pensar en el arcaísmo típico del lenguaje oficial, al igual que hay que considerar como hiperbólicas las designaciones de madin a, también en el lenguaje oficial de la época, a Ṭalŷayra y Madīnat al-Fatḥ, en realidad campamentos, e independientemente de las connotaciones ideológicas que se daban en esos dos casos. De todas formas, Qal'at Jalīfa será la última qal' $a$ que se levante en al-Andalus.

Más problemática resulta la interpretación de la "qal 'a en Ŷayyān» que junto con el maŷšar de Wādī Šawš otorgó Artobás al antecesor de los Banū Ḥazm ${ }^{26}$,

\footnotetext{
${ }^{20}$ Guichard, P., Al-Andalus. Estructura antropológica de una sociedad islámica en Occidente, Barcelona, 1976, 368-369.

${ }^{21}$ Aquí con la alternancia hișn al-Ḥanaš.

${ }^{22}$ Ibn Hayyān, Al-Muqtabas (V), 122.

${ }^{23}$ Sobre esta última, Gutiérrez, S., La cora de Tudmūr: de la Antigüedad tardía al mundo islámico. Poblamiento y cultura material, Madrid-Alicante, 1996, 230-233.

${ }^{24} \mathrm{Ibn}$ al-Jạtīb, Al-Ihạta fi ajbär Garnäta, ed. M. 'A. 'Inān, t. IV, El Cairo, 1978, 39. 193.

${ }^{25}$ Chalmeta, P., «Después de Simancas-Alhandega. Año 328/938-940", Hispania, 144 (1980),

${ }^{26} \mathrm{Ibn}$ al-Qūtīya al-Qurtubīi, Ta'rỉ̆ iftităh al-Andalus, Madrid, 1868, 39.
} 
puesto que la primera lectura sugiere una posesión particular que se transfiere a otro individuo y, asimismo, que en época visigoda existía algo que se podía identificar con una qal 'a. Independientemente de los problemas de traducción, puesto que Artobás no pudo pronunciar nunca las palabras que se ponen en su boca, el mismo texto proporciona una buena pauta, ya que con respecto al may̌šar se enumeran sus componentes, a saber, ganados, vacas y siervos, mientras que de la qal' $a$ no se dice que tuviera nada. En otras palabras, el maŷšar que entrega Artobás es un dominio feudal, o protofeudal si se prefiere, pero la qal' $a$ es un simple asentamiento, donde se instalaron los Banū Ḥazm.

Creo, por tanto, que se puede mantener la caracterización de qal'a como asiento de la población conquistadora, con escaso valor defensivo, y quizá por ello su rápido abandono o transformación en hușūn o mudun. Posiblemente se deba también a esas rápidas transformaciones la dificultad para identificarlas arqueológicamente, sobre lo cual contamos tan sólo con lo publicado por Agustín Sanmiguel acerca de la primitiva Qal 'at Ayyūb, de donde se deduce un tamaño reducido y un aislamiento intencionado ${ }^{27}$, características que vienen a coincidir con las que extraíamos de las fuentes escritas.

Otras referencias a los primeros asentamientos también parecen coincidir con la función original de los qilā', y así al-Maqqarī, refiriéndose a la conquista del Norte de la Península, afirma que «los árabes se establecieron en los pasos más difíciles", y a un nivel más general, que «los árabes y los beréberes, cuando pasaban por un paraje que les parecía bien, fundaban allí un pueblo y se establecían en él" ${ }^{28}$, lo que se repite en el propio al-Maqqarī y en la Risala del Embajador Marroquí, donde, tras la partida a Oriente de Mūsà y Țâriq, se dice: «quedaron en el país de alAndalus todos los que quisieron establecerse en él, en los lugares que habían fundado y poblado" (wa-aqāma ma'a-humā bi-balad al-Andalus kull man arāda

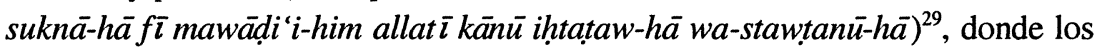
aspectos estratégicos coinciden bien con la función que le dábamos a la línea Qal 'at Rabāḥ, Qal'at 'Abd al-Salām y Qal'at Ayyūb, y la insistencia en las nuevas fundaciones no se puede referir nada más que a los qilā'.

Así pues, en un primer momento los grupos conquistadores se establecen en las ciudades y en lo que podemos denominar como un poblamiento intercalar, en lugares de nueva fundación entre esas ciudades. Da la impresión, a partir del

${ }^{27}$ Sanmiguel Mateo, A., "El posible emplazamiento del núcleo originario de Calatayud", en Segundo Encuentro de Estudios Bilbilitanos. Actas, t. I, Calatayud, 1989, 149-162, y «Apuntes sobre la evolución urbana del Calatayud islámico", en Simposio internacional sobre la ciudad islámica, Zaragoza, 1991, 451.

${ }^{28}$ Apéndice II a Ajbar Machmuâ, 193.

${ }^{29} \mathrm{Ibn}$ al-Qūtịya, 210. 
esquema resultante, que se trata de un procedimiento intermedio entre el primitivo sistema de establecimiento en amșär y la práctica siria de ocupación de las antiguas ciudades, lo que se aviene bastante bien con las nuevas orientaciones de la rama Marwāní de los Omeyas.

Por lo que respecta a la población indígena, he expuesto en diversas ocasiones cómo las fuentes dicen, a veces con carácter general, y otras refiriéndose a zonas concretas, que buena parte de la población huyó a los montes en el momento de la conquista. Esto es algo que ha podido comprobar la arqueología, ampliándolo a un movimiento que se venía dando desde antes pero que, efectivamente, la conquista musulmana viene a intensificar. Son los conocidos h̆ușün-refugio, con un ajuar cerámico reducido y técnicamente limitado, que es lo que llamamos vajilla de torno lento. La toponimia también los descubre bajo los nombres de Munt- o Šant-, y yo mismo los he cartografiado para la actual Andalucía, de donde se desprendía una notable concentración en Andalucía Oriental, frente a una presencia muy reducida en la parte Occidental, al contrario de lo que ocurría con la distribución de los $q i a^{-30}$. Y sobre la antigüedad de tales asentamientos, además de los datos sobre la conquista, se nos dice en varias ocasiones que habían sido "desde siempre de los cristianos" ${ }^{31}$, en lo que redundan también las descripciones de husūun con iglesias, como Šant Bịtr en Ŷazīrat Qādis, que poseía una iglesia antigua ${ }^{32}$, o el Šant Ištỉban frente a Ilbīra, que se considera el lugar de procedencia de la inscripción de la Alhambra que alude a un grupo basilical ${ }^{33}$.

Pero parece indudable que no toda la población optó por esa posibilidad, y en principio sabemos de la continuidad de las principales ciudades, donde, como se ha dicho, se van a instalar también grupos de los conquistadores. Sin embargo, sobre el sentido de esa continuidad las noticias son contradictorias, y así, sobre Málaga, se nos dice que en el momento de la conquista no había nadie ${ }^{34}$, si bien sí tenemos la constancia de algún poblamiento para la mayoría de ellas, puesto que serán los puntos preferentes de la conquista. En favor de esa continuidad tenemos la nómina de obispos, con sus respectivas sedes, para el s. IX, que, entre los asistentes al Concilio de Córdoba del 839 y los enumerados por el abad Samsón en su Apologético, se cuentan prácticamente la totalidad de las que

\footnotetext{
${ }^{30}$ Recientes estudios, 369; y más detallado en aLa islamización del SE de al-Andalus. Los datos arqueologicos", en Boldrini, E.-Francovich, R. (eds.), Aculturazione e mutamenti. Prospettive nell'archeologia medievale del Mediterraneo, Florencia, 1995, 13-28.

${ }^{31}$ Ibn Hayyān, Al-Muqtabas (V), 223.

${ }^{32}$ Molina, L., Una descripción anónima, 65.

${ }^{33}$ García Moreno, L. A., "Propaganda religiosa y conflicto político en la epigrafía de época visigoda", en Religio Deorum. Actas del Coloquio Internacional de Epigrafia (Culto y sociedad en Occidente), Sabadell, 1992, 201.

${ }^{34}$ Ajbar Machmua, 25.
} 
existían al final de la época visigoda ${ }^{35}$. No obstante, la presencia de obispo no implica mecánicamente la continuidad de la sede, puesto que entre los de la relación antedicha se encuentra incluso el obispo de Urci, ciudad que indudablemente ya había desaparecido. Y asimismo, alguna otra noticia histórica hace poner en duda la continuidad de alguna ciudad antigua, como la referente a Šadūna ${ }^{36}$, que en el año 136 (753-754) fue utilizada como refugio por la 'ämma («el bajo pueblon) de al-Andalus ${ }^{37}$, lo que indica, como mínimo, una baja densidad de población como para poder acoger a esa 'ämma.

Por otra parte, la primitiva toponimia árabe trasluce la decadencia de algunas de esas sedes, que pasan a ser designadas como hișn o qarya, de donde podemos deducir, además de la escasez de población, su ruralización. Así, Tucci (Martos) pasa a ser un hissn, que en al-Rāzī se convierte tan sólo en una "sierra", cuidando de poner en el pasado la existencia de vida urbana: « $E$ ay fue una çibdat muy antigua e agora fallan y rastros antiguos ${ }^{38}$. Castulona igualmente es hișn ${ }^{39}$, y si bien se puede aducir que ya en época visigoda dejó de ser sede episcopal en favor de Baeza, esta última es una qarya; Iliturgi desaparece, y cuando surge Andújar es bajo la forma de hișn ${ }^{40}$. Recordemos también que Egabrum (Priego) aparece en el momento de la fitna como hisn, pero que ya en época visigoda se había dado la disociación entre la ciudad y la nueva aristocracia apegada al mundo rural ${ }^{41}$. Pero incluso para varias de las que aparecen con la terminología de madina, su función urbana es bastante dudosa, y en algunos casos esa terminología parece ser que se desprende de las obras de fortificación que realiza en ellas Sawwār b. Ḥamdūn, ya en el s. IX, tal Muntī̌sa, Basta o Acci ${ }^{42}$, pasando a denominarse esta última madīnat Banī Sāmī, mientras que con el Wādī Āš se designaba el valle.

\footnotetext{
${ }^{35}$ Son confirmantes del Concilio de Córdoba los obispos de las sedes andaluzas siguientes: Sevilla Guadix, Écija, Córdoba, Priego, Málaga y Elvira; apareciendo además en Samsón los de Medina Sidonia, Baza, Baeza, Martos y Urci. Gil, I., Corpus Scriptorum Muzarabicorum, «Res Muzarabicae, B. Nomina locorum", t. II, Madrid, 1973, 719-720. Las sedes de época visigoda en Salvador Ventura, F., Hispania meridional entre Roma y el Islam. Economía y sociedad, Granada, 1990, mapa 7. 61.

${ }^{36}$ La Asidonia "fortissima civitas» de época visigoda; Salvador Ventura, F., Hispania meridional,

${ }^{37}$ Lévi-Provençal, E., La Péninsule Ibérique, trad., 123.

${ }^{38}$ Crónica del moro Rasis, ed. Catalán, D., y de Andrés, M. S., Madrid, 1975, 34; también Priego para al-Rāzī es «castillo", 27, pero seguramente alude a la época califal.

${ }^{39}$ Vallvé Bermejo, J., «La cora de Jaén", 73.

${ }^{40}$ Salvatierra Cuenca, V.-Castillo Armenteros, J. C., «Arqueología urbana e historia. El caso del Jaén islámico”, en Coloquio Hispano-Italiano de Arqueología Medieval, Granada, 1992, 114.

${ }^{41}$ Gil, J.-González, J., «Inscripción sepulcral de un noble visigodo de Igabrum», Habis, VIII (1997), 455-461.

${ }^{42}$ Ibn al-Jatīi , Al-Ihậta, t. IV, 270.
} 
Los datos arqueológicos coinciden en esa decadencia, y ya he señalado en otro lugar ${ }^{43}$ cómo a partir de la arqueología urbana se observa una dificilísima recuperación de madinnat Mālaqa con anterioridad al s. XI.

Este panorama de la problemática continuidad de las ciudades antiguas, lógicamente refuerza la evidencia contraria de la huida de la población a los montes, pero aun así no deja de ser inquietante la insistencia por parte de los conquistadores de ubicar 'ummal o gobernadores en esas mismas ciudades. Desde mi punto de vista, no encuentro nada más que una explicación, y ésta de carácter fiscal, tratando de conseguir con la simbiosis 'ämil-obispo la conjunción de poder coactivo, censos y diezmos. En favor de esta hipótesis tenemos la sintonía de la jerarquía eclesiástica y poder islámico, prácticamente en todas las épocas, pero además, permite explicar los primeros asentamientos en la Tarraconense y también, pese a su realidad material, en la Bética. Para esta última se ha ofrecido más arriba una relación de ciudades con gobernadores, de las cuales la única que no era sede episcopal es Carmona; fuera de la Bética, pero en el mismo sur de al-Andalus, Beja también posee gobernador árabe, y las construcciones de Sawwār b. Ḥamdūn en Baza, Mentesa y Guadix son lógicamente para la población árabe. Tenemos pues constancia de establecimientos árabes en todas las sedes episcopales de época visigoda, con las únicas excepciones de Itálica, de donde vendrá quizá su conversión en el hișn de Santiponce aprovechando la fortificación de Leovigildo ${ }^{44}$, y Urci, por donde no pasaron los conquistadores musulmanes, que desaparece.

Sin embargo, en escaso margen de tiempo ese esquema inicial se verá sustituido por otro, observándose con bastante nitidez esos cambios a través de las noticias que poseemos sobre la Marca Superior. Aquí, la pasividad mostrada por Córdoba ante el paso de Gerona a manos francas, se confirma con la mayor información que tenemos para Barcelona, donde la resistencia mostrada por la población de la ciudad y su gobernador no encontrará ningún apoyo en el Estado cordobés, lo que se ratifica con la práctica de éste en los años siguientes, optando claramente por el botín y el saqueo, frente a la posibilidad de volver a controlar directamente ambas ciudades. Pero el cambio más notable se operará en la forma de control del territorio, realizándose éste ahora mediante grandes linajes muladíes, apareciendo como intermediarios de Córdoba, personajes como los Banū Qasī, los Banū 'Amrūs o Šabrị̂t ${ }^{45}$.

${ }^{43}$ La islamización del SE de al-Andalus, 25-26.

${ }^{44}$ Salvador Ventura, F., Hispania meridional, 54.

${ }^{45}$ Sobre ellos, Manzano Moreno, E., La frontera de al-Andalus en época de los Omeyas, Madrid, 1991, en especial el apartado «El final de la preponderancia política de los linajes árabes de la Frontera Superiorn, 231-233. 
La explicación de estos cambios creo que se debe encontrar en una mejor adecuación a la realidad existente, heredera del protofeudalismo visigodo, o sea, la ruralización de la sociedad y la nueva aristocracia de base rural, fenómeno que es indudable en el ejemplo más conocido de los Banū Qasī, en cuyo territorio no habrá ningún medio urbano hasta la creación de Tudela, a instancias del Estado cordobés.

Estos cambios son de sobra conocidos por los historiadores, y se suelen justificar como resultado de la situación fronteriza y las consecuentes influencias externas, al menos a nivel de la clase dirigente. Sin embargo, esos mismos cambios tienen lugar en una zona tan alejada de la frontera como el Suroeste peninsular, donde sabemos por Ibn al-Qūtīya que desde un primer momento se gobernó por jefes árabes ubicados en Niebla y Beja, al menos hasta la revuelta pro-'abbāsí de al-'Alà b. al-Mugīt al-Ŷudāmīi ${ }^{46}$, pero al poco tiempo serán sustituidos por linajes muladíes, como los Bakríes y otros, que terminarán entrando en la órbita de los Ŷillíqíes. Por tanto, las modificaciones que tienen lugar en la Marca Superior no son tan excepcionales, y se deben enmarcar en un cambio de estrategia para el control de los territorios, ahora más apegada a la realidad.

No obstante, la solución de grandes linajes muladíes, intermediarios de Córdoba y controladores de los territorios por medios que desconocemos, no fue la única ensayada, y en la zona de la actual Andalucía, en esa modificación del esquema originario tendrá un lugar destacado el asentamiento de los ŷundíes.

Como es sabido, a partir del reparto de Abū l-Jațtār, los nuevos llegados se establecerán en los límites del valle del Guadalquivir, ampliando y completando los anteriores asentamientos de los baladíes. Uno de los textos más fiables sobre estos nuevos asentamientos, el de Ibn al-Qūtīya, expresa que se hicieron "en los bienes de los dimmies cristianos" (wa-käna inzälu-hum 'alà amwäl ahl al-dimma min al-'aŷam), diferenciándolos claramente de los anteriores, que tuvieron lugar en sus gana' im, es decir, en tierras conquistadas como botín $n^{47}$. Lógicamente, la nueva instalación se debió ver favorecida por la huida de la población indígena a los montes, ya comentada, y, en efecto, como afirma Ibn al-Jatīib para el ŷund de Damasco, de inmediato se dispersaron por las qurà y comenzaron a cultivar la tierra ${ }^{48}$. Sobre esta dispersión se volverá a continuación, pero por lo pronto conviene destacar, frente al esquema anterior, la escasa atención prestada a las

\footnotetext{
${ }^{46}$ Ibn al-Qūtīya, 30-31.

${ }^{47}$ Ibn al-Qựìya, 20.

${ }^{48} \mathrm{Ibn}$ al-Jạtib, Al-Ihăta, t. I, El Cairo, 1973, 106-107, donde precisa que recibieron un tercio de los mu'ahidūn.
} 
antiguas ciudades. Así, el centro del yund del Jordán será Archidona, frente a Málaga; en la ubicación del de Qinnasrīn comienza a surgir Ŷayyān, frente al resto de las sedes episcopales de la zona, y en el área del de Palestina, ya se ha visto el abandono de Šadūna ${ }^{49}$, y comenzará la presencia de Qalsāna.

Se acaba de decir que los ŷndíes se dispersaron por las alquerías y, en efecto, en las zonas ocupadas por éstos empiezan a surgir en los textos multitud de ellas. La toponimia nos permite discernir sobre su origen, observando la continuidad o reocupación de antiguas villae, mediante la constatación de antropónimos latinos y el sufijo -ana, como, entre otras muchas, en la que se instaló el abuelo de Sawwār, Caparacena, en la región de Ilbīra ${ }^{50}$; en el relato de los antepasados de al-'Udrī, éstos ocupan qaryat Ŷilyāna ${ }^{51}$, y los descendientes del wăl $\bar{l}$ 'Abd alRaḥmān al-Gāfiqii dieron nombre, en el Aljarafe, a Muranānat al-Gāfiqiyyīñ ${ }^{52}$. Una noticia sobre los conflictos entre 'Abd al-Rahmān al-Dājil y los yahṣubíes parece indicar que este tipo de asentamientos fue tan frecuente como para que la gente extendiera indiscriminadamente la terminología, pues al-Dājil se estableció «en la qarya B.nnas (¿Viñas o Peñas?), en el barrio (hära) que se conoce por alRakūnīn, y que el vulgo ('ämma) lo llama al-Rakākana" ${ }^{53}$.

De todas formas, sobre la temprana presencia árabe en qurà con topónimo latino las citas son abundantes, como las repetidas Țurruš, que indican antiguas fortificaciones, o la qarya Kintuš Ma'āir, un Quintus de los ma 'āfir, a la que se alude con motivo del ataque de los maŷūs a Sevilla, y en la que había una iglesia antigua ("wa-bi-hā kanissa awwaliya») $)^{54}$. Las noticias referentes a iglesias tampoco faltan, y en Constantina, además del topónimo, también quedaban restos de una ${ }^{55}$, pero además, la relativa frecuencia de topónimos como Kanīsa o al-Dayr, sugieren otro origen de qurà a partir de centros religiosos, pero ahora con poblamiento árabe, como se nos dice de los gāfiqíes Banū Mūsà, de Kanīsat al-māă ${ }^{, 56}$.

\footnotetext{
${ }^{49} \mathrm{La}$ fecha de ocupación por la 'āmma es casi inmediata al establecimiento del ŷund de Palestina, y para la época del emir al-Ḥakam el qāọīestá asentado en Algeciras, según la biografía que ofrece alJušanī de 'Ubayd Allăh b. Mūsà al-Gāfiqī, Aljoxani, Historia de los jueces de Córdoba, trad. J. Ribera, Madrid, 1965, 316.

${ }^{50}$ Ibn al-Jạtīb, Al-Iḥạta, t. IV, 270.

${ }^{51} \mathrm{Al}$-'Udrī, 90.

52 Ibn al-Qūtīya, 13 y 76.

${ }^{53}$ Ibn al-Qūtìya, 31. De ello se puede deducir también que con la nueva designación de qarya se englobaban antiguos asentamientos, ahora convertidos en hârät; a lo que puede aludir también otro pasaje sobre los ancestros de al-'Uḍn̄, en qaryat Dilāya, junto a Šibāriya Diyu y al-Malāt, de los 'aŷam, aunque aquí no se nos dé la designación topográfica; al-'Ud̆rī, 91-92.

${ }^{54}$ Ibn al-Qūtīya, 64.

${ }^{55}$ Lévi-Provençal, E., La Péninsule Ibérique, 172.

${ }^{56}$ Ibn al-Qūtīya, 75, donde especifica que eran «min bayt min al-'arab».
} 
La aparición de qurà sobre asentamientos anteriores no se debe interpretar sin más como continuidad del poblamiento, sino más bien como transformación, pues, si efectivamente los musulmanes a su llegada encontraron algo a lo que denominaron qurà, como en el caso del ataque de Mugīt a Córdoba, que acampó entre (bayna) qaryat Šaqunda y qaryat Țarsayl ${ }^{57}$, parece ser que con ello lo que traducían era el uicus, término que todavía utilizará Eulogio en el s. IX, así el Ausinianus uicus $^{58}$. En realidad, los términos que con seguridad implican una continuidad en las formas de poblamiento rural visigodo se reducen a dos, day ' $a$ y qașr: con el primero se nombran las famosas tres mil posesiones de los vitizanos, pero se limita a eso y a lo que consigue, no sabemos cómo, algún importante personaje, como el wāl $\bar{\imath}$ Yūsuf al-Fihrī, el cual, según Ibn al-Jatīî, "tenía en Granada, cuando su gobierno, diya $a^{-}$que frecuentaba» 59 . El segundo término se utiliza como traducción de castrum, lo que es evidente en la evolución del topónimo de la actual Casarabonela, que procede de Castra Vinaria a través de Qașr Bunayra, y otro al-Qașr aparece en la campaña de Algeciras de 'Abd alRaḥmān III. El término utilizado nos ilustra sobre el carácter palaciego y residencial del castrum visigodo, pero sin embargo evolucionan pronto en el mundo andalusí, pues el pomposo Qașr Bunayra se convierte en un simple hișn ${ }^{60}$, al igual que el futuro califa construirá un hịsn a partir de Qaštruh Dakwān ${ }^{61}$, mientras que del al-Qașr sólo sabemos que pertenecía a los aḥwāz de Algeciras ${ }^{62}$, por lo que debemos considerarlo como una qarya, pero sin excluir la posibilidad de hișn.

Los escasos datos arqueológicos con que contamos también hacen referencia a la reocupación de asentamientos de época romana que habían estado abandonados, antes que a la continuidad, pues si bien es verdad que van a pervivir edificios religiosos $^{63}$ al igual que la población mozárabe que los usa, en la mayoría de los yacimientos lo que se observa es lo contrario; en la villa de Manguarra y San José, que tuvo su florecimiento en el s. IV, y que debió abandonarse «no muy avanzado el $\mathrm{S}$. $\mathrm{V}^{64}$, se encontró cerámica islámica de primera época ${ }^{65}$, pero nada de visigodo;

${ }^{57}$ Ajbar Machmua, 10

${ }^{58}$ Memoriale Sanctorum, II, 8, en Gil, I. (ed.), Corpus Scriptorum Muzarabicorum, 409-410.

${ }^{59}$ Al-Ihatta, t. IV, 340.

${ }^{60}$ Ibn Ḥayyān, Al-Muqtabas (V), 181

${ }^{61}$ Ibn H̦ayyān, Al-Muqtabas (V), 169

${ }^{62}$ Ibn Hayyān, Al-Muqtabas (V), 87.

${ }^{63}$ Sobre ellos, Caballero Zoreda, L., «Pervivencia de elementos visigodos en la transición al mundo medieval. Planteamiento del tema", en III Congreso de Arqueología Medieval Española. Actas, t. I Ponencias, Oviedo, 1989, 111-134.

${ }^{64}$ Serrano Ramos, E.-de Luque Moraño, A., «Una villa romana en Cártama (Málaga)”, Mainake, I (1979), 164

${ }^{65}$ Acién Almansa, M., Recientes estudios, 359. 
tampoco lo hay en la antigua Singilia Barba, la Sanŷla de época emiral ${ }^{66}$, al igual que sucede en Bezmiliana, donde un solo fragmento de sigillata hispánica atestigua la época del topónimo, pero en los niveles inferiores lo que aparece es cerámica emiral ${ }^{67}$, mientras que en Baŷȳāna no queda nada más que el topónimo romano, convertido en qarya por los yemeníes en el s. IX, y a continuación en madina ${ }^{68}$.

Junto a la reocupación de antiguos asentamientos, existen también las qurà de nueva creación, lo que es indudable en la Billa Nūba de los Bahríes, en la zona de Sevilla ${ }^{69}$, y bastante probable mediante la proliferación de topónimos árabes. De todas formas, la superposición del mapa de topónimos, de cualquier origen, referidos al s. VIII, sobre el de localidades, conocidas a partir de cualquier indicio, de época visigoda, evidencia que se ha producido una multiplicación de los lugares de poblamiento, fundamentalmente de carácter rural.

Esta constatación de carácter general resulta aún más clara en las zonas ocupadas por los ŷundies, y de ahí que se pueda pensar en otra variante para el control del territorio, la que se da en la actual Andalucía por medio de los ŷundies, que sustituyen aquí a los grandes linajes muladíes del valle del Ebro y del Suroeste peninsular, y en ambas variantes juegan un escaso papel las antiguas ciudades y sus obispos.

La sustitución del binomio 'ámil-obispo, que caracterizó la primera fase de ocupación del territorio, por otra fórmula más ajustada a la realidad, que se materializa en las dos versiones de alianza del gobierno con los grandes linajes muladíes y yundíes encargados de la recaudación de impuestos ${ }^{70}$, será una de las causas de que continúe la decadencia de las antiguas ciudades y, como se ha visto, que la toponimia árabe exprese su ruralización.

Para el marco geográfico en que se plantea este estudio es difícil observar la primera fase señalada, puesto que de inmediato la siguiente opción de control del territorio transformará la situación. Tan sólo podemos dejar constancia de que la, ya aludida, desaparición de la sede de Urci coincide con la nula presencia de conquistadores en ese extremo Sureste de la Península, pues, como es sabido, el itinerario seguido fue Málaga, Ilíberis y pacto con Teodomiro, sin que dicho

${ }^{66}$ Atencia Páez, R., La ciudad romana de Singilia Barba (Antequera, Málaga), Málaga, 1988.

${ }^{67}$ Acién Almansa, M.-Martínez Madrid, R., "Cerámica islámica arcaica del sureste de al-Andalus", Boletín de Arqueología Medieval, 3 (1989), 123-135.

${ }^{68}$ Molina López, E., «Noticias sobre Baŷȳāna (Pechina-Almería) en el "Iqtibās al-anwār" de alRušātīi. Algunos datos historiográficos", Revista del Centro de Estudios Históricos de Granada y su Reino (2.. época) 1 (1987), 119.

${ }^{69} \mathrm{Ibn}$ al-Qūtīya, 26.

${ }^{70}$ Manzano Moreno, E., «El asentamiento y la organización de los ŷund-s sirios en al-Andalus", $A l$ Qantara, XIV (1993), 327-359. 
espacio entrara en el tratado. La primera noticia de presencia árabe en la zona es la concesión tardía, ya con 'Abd al-Raḥmān II, de lo que se denominará Urš alYaman, concesión que indica un cierto vacío, y donde esos yemeníes crearán las qurà de Baŷȳāna y Mūra ${ }^{71}$.

Sin embargo, sobre esa primera fase poseemos una información privilegiada, que es la referente a lo que fue el noreste de al-Andalus y la documentación emanada con motivo de la conquista franca. Para la mayoría de los historiadores que se han acercado al tema, se trata de un simple hiato, en el que no pasa nada, salvo quizá la pervivencia de lo visigodo, pudiendo extraerse a partir de ello las consecuencias más ideológicas ${ }^{72}$, y algún autor llega incluso a asombrarse de que Narbona y Barcelona se resistieran a la conquista rranca $^{73}$. Desde otro punto de vista, Miquel Barceló advirtió que «a pesar del profundo declive de las ciudades fue precisamente en ellas donde capitula y es derrotada la clase dominanten, y que "parece existir un primer momento, nada estudiado, en el que la administración arabo-musulmana utiliza la medina como elemento ordenador del territorio" ${ }^{74}$. En efecto, según Ramón d'Abadal, las cuatro sedes que perviven a la restauración franca, Barcelona, Gerona, Elna y Urgel, "corresponden a los centros urbanos más importantes del país" ${ }^{75}$, y "urbanísticamente sólo dos ciudades presentan una cierta importancia, Barcelona y Gerona" ${ }^{76}$, precisamente las dos que contaron con gobernador árabe.

Barcelona además "va a adquirir una creciente importancia política, en detrimento de la próxima y decadente capital provincial de Tarragona. Proceso que no fue interrumpido por la invasión árabo-musulmana, sino que se acelerará", en palabras de Eduard Riu ${ }^{77}$. Lo problemático aquí es la rápida desaparición de

${ }^{71}$ Molina Lopez, E., Noticias sobre Baŷyāina, 123.

${ }^{72} \mathrm{M}$. Rouche termina su trabajo "Du royaume de Tolède à la future Europe (VII'-VIII ${ }^{\mathrm{e}}$ siècles)", en L'Europe héritière de l'Espagne wisigothique, Madrid, 1992, 50, con la siguiente frase: "En somme la pérdida de España resultó ser la salvación de España".

${ }^{73}$ Salrach i Marés, J. M., El procés de formació nacional de Catalunya (segles VIII-IX), El domini carolingi, Barcelona, 1978, 25, lo que contrapone a las ciudades que "se liberaron voluntariamente", Nîmes, Magalona, Agde, Béziers y Gerona, aunque no dice que las actualmente francesas incluidas en la relación, fueron incendiadas con anterioridad por Carlos Martel.

${ }^{74}$ "Visigodos y árabes en el proceso de formación de Cataluña", en Barceló, M. (dir.), Historia de los pueblos de España. Los antiguos territorios de la Corona de Aragón. Aragón, Baleares, Cataluña, País Valenciano, Barcelona, 1984, 222.

${ }^{75}$ d'Abadal i de Vinyals, R., Catalunya carolíngia, t. I, Barcelona, 1986, 241.

${ }^{76}$ d'Abadal i de Vinyals, R., "La institució comtal carolíngia en la pre-Catalunya del s. IX", Anuario de Estudios Medievales, 1 (1964), 71.

${ }^{7}$ Riu i Barrera, E., "La ciutat de Barcelona, de la Urbs romana a la capital Comtal (s. V-XIII)", en IV Congreso de Arqueología Medieval Española. "Sociedades en transición». Dossier. Resúmenes, Alicante, 1993, 43. Matizaciones sobre la decadencia de la Tarraco tardoantigua se pueden ver en Guitart Durán, J., "La ciudad romana en el ámbito de Cataluña", en La ciudad hispanorromana, Barcelona, 1993, 77-78, y Pinyol, J., "La caiguda de Roma i el benestar dels 
la capital, Tarraco, que se ha querido explicar por su situación fronteriza ${ }^{78}$, aunque en realidad fue anterior ${ }^{79}$, y la situación fronteriza no fue óbice para el posterior desarrollo de Tortosa, al igual que anteriormente no lo fue para Barcelona, como ha quedado dicho, y también la urbanísticamente importante Gerona que encuentra d'Abadal se ha transmitido tras la ocupación musulmana.

Quizá sea más apropiado pensar en una situación semejante a la de Urci, es decir, en la no presencia musulmana en la ciudad, y en este caso concreto debido a la huida del obispo Próspero $^{80}$, lo que imposibilitó la simbiosis 'ámil-obispo.

Sobre la actividad de los obispos de las antiguas Tarraconense y Narbonense bajo el gobierno de al-Andalus prácticamente la única noticia que poseemos es la de la muerte de Nambadus, obispo de Urgel, quemado en Llivia por el wāli Munuza $^{81}$, pero la rebelión de este gobernante beréber se hizo contra el Estado cordobés, y contó con la oposición de los sarraceni y cristianos de Septimania, motivo por el cual fue enviado a las llamas ${ }^{82}$, de donde se deduce una sólida fidelidad de Nambadus con respecto a Córdoba. Una fidelidad parecida debieron mostrar los prelados de la Narbonense, puesto que Carlos Martel, en su retirada del infructuoso sitio de Narbona del 737, destruyó y quemó las iglesias de Béziers, Agde, Magalona y Nîmes ${ }^{83}$, es decir, las sedes episcopales, lo que realizó, en opinión de Ramón d'Abadal, "seguramente en castigo a la lealtad que los indígenas habían mostrado hacia sus dominadores musulmanes" ${ }^{84}$, si bien la elección de objetivos deja pocas dudas de que dicha lealtad la compartían los indígenas con la jerarquía eclesiástica. El mismo autor señala que la estructura eclesiástica de Septimania debió desaparecer con motivo de las guerras de conquista franca, por lo que sentencia, para la misma iglesia, que «si les debió ser suave el tránsito al dominio árabe, fue muy duro, por el contrario, el paso al dominio franco" ${ }^{85}$.

En otras ocasiones, la ausencia de noticias sobre los obispos parece obedecer a causas semejantes a las anteriores, siendo sospechoso que en las diversas versiones sobre la entrega de Gerona a los francos, se citen sólo a los homines de

provincials. Reflexions després de l'exemple del conuentus de Tarraco», Estudios de la Antigüedad, 1 (1984), 89-156.

${ }^{78}$ Freedman, P., «L'influence wisigothique sur l'Eglise catalane», en L'Europe héritière, 70. 1991.

${ }^{79}$ Aquilué, X.-Dupré, X.-Massó, J.-Ruiz de Arbulo, J., Tarraco. Guía Arqueológica, Tarragona,

${ }^{80}$ Valls i Taberner, F., Marca hispánica, Barcelona, 1987, $25-26$.

${ }^{81}$ Gross, M., «Les Wisigoths et les liturgies occidentales", en L'Europe héritière, 133-134.

${ }^{82}$ d'Abadal i de Vinyals, R, «El paso de Septimania del dominio godo al franco a través de la invasión sarracena, 720-768", Cuadernos de Historia de España, XIX (1953), 27.

${ }^{83}$ d'Abadal i de Vinyals, R., "Catalunya carolíngia", t. I, 96.

${ }^{84}$ d'Abadal i de Vinyals, R., "El paso de Septimania", 38 y 41.

${ }^{85}$ d'Abadal i de Vinyals, R., "Catalunya carolíngia», t. I, 95 y 96. 
la ciudad y que los redactores eclesiásticos hubieran olvidado el protagonismo de la jerarquía ${ }^{86}$. Y de la misma manera resulta dificultoso aludir a la prudencia eclesiástica cuando coinciden las fuentes, francas y musulmanas, en citar sólo a gobernantes musulmanes de las ciudades de la Marca Superior en sus visitas de flirteo a las cortes de Aquisgrán, Paderborn o Tolosa. E igualmente, en el atroz cerco que hubo de sufrir la ciudad de Barcelona, lo que resulta curioso no es que se defendiera, sino la impresión de coherencia de la población que revelan las fuentes, sin que se aluda nunca a un partido profranco, ni mucho menos a clérigos pactistas, y ello pese al consciente abandono de Córdoba ${ }^{87}$.

Por tanto, las noticias que poseemos, así como los silencios, parecen indicar una connivencia entre jerarquía eclesiástica y Estado musulmán, lo cual, por lo demás, no es nada novedoso en la historia de al-Andalus, puesto que incluso en las contumaces rebeldías de Toledo nunca aparece la iglesia. Pero es justo preguntarse cómo se consiguió tal connivencia.

En principio, se aprecia una cierta reticencia por parte de los francos a la hora de restablecer las diócesis en los territorios conquistados, con las excepciones de Narbona y Urgel. El caso de la primera, restablecida por el propio conquistador, Pipino, se explica por el papel que debía jugar dicha sede en la subsiguiente conquista de Aquitania, mientras que la excepción de Urgel quizá tenga algo que ver con el peso de su obispo Félix, para cuya destitución se hubieron de movilizar todas las fuerzas del Imperio en un famoso conflicto teológico. Pero para las restantes la reposición será tardía, después del 810 en Elna, Gerona y Barcelona ${ }^{88}$, cuando Elna debió ser conquistada tras la toma de Narbona en el $759^{89}$, y Gerona lo fue en 785. Indudablemente, esa tardanza no se da en la pareja institución condal, como es sabido por el inmediato nombramiento de Bera en Barcelona, mientras que en Gerona sabemos que al menos en 801 ya estaba un tal Rostany, que participó en la conquista de Barcelona ${ }^{90}$.

El desfase en la reposición de una institución y otra parece claro, y de ahí la impresión de reticencia. Sin embargo, esta impresión se contradice con los importantes beneficios fiscales con que se van a encontrar los obispos en su

\footnotetext{
${ }^{86}$ Cronicón de Moissac, "Gerundenses homines Gerundam civitatem Carolo regi tradiderunt”; Annales Barcinonenses, «Gerundam civitatem homines tradiderunt regi Karolo"; d'Abadal i de Vinyals, R., «Catalunya carolíngia”, t. I, 83; Salrach i Marés, J. M., «El procés de formació nacional», t. I, 135, n. 36.

${ }^{87}$ d'Abadal i de Vinyals, R., «Catalunya carolíngia», t. I, cap. IV, «L'ocupació de la ciutat de Barcelona", 183-216. Sobre la cronología, Wolff, Ph., «Les événements de Catalogne de 798-812 et la chronologie de l'Astronome», Anuario de Estudios Medievales, II (1965), 451-458.

${ }^{88}$ Freedman, P., "L'influence wisigothiquen, 70.

${ }^{89}$ d'Abadal i de Vinyals, R., "Catalunya carolíngia», t. I, 242.

${ }^{90}$ d'Abadal i de Vinyals, R, "Catalunya carolíngia”, t. I, 197.
} 
reposición. Los concedidos al de Narbona han dejado perplejos a los investigadores, calificándolos, por parte de d'Abadal, como "concesión especial, poco acostumbrada en los preceptos reales de inmunidad" ${ }^{91}$, y J. M. Salrach, como "un privilegio muy lucrativo" ${ }^{92}$. Pero las catedrales catalanas no le fueron a la zaga, habiendo resumido Ramón d'Abadal los privilegios fiscales obtenidos ${ }^{93}$, lo que interpreta Paul Freedman como que "la ley de Egica, que aseguraba a los obispos un tercio de los ingresos de la iglesia, después del 800 fue simplemente extendida a los ingresos del condado" ${ }^{94}$.

Parece ser que la contradicción entre reticencia y dotación no se puede explicar nada más que de una manera, y ésta no es una concesión ex novo por los conquistadores, sino que es el restablecimiento de lo que tenían en el momento anterior, con los musulmanes, por lo que se pueden comprender las razones de las lealtades ya indicadas, y las reticencias de los nuevos dominadores, a las que hubieron de ceder.

Como vemos, la privilegiada documentación franca nos informa sobre la primera fase de ocupación del territorio y la insistencia en las ciudades por parte de los conquistadores musulmanes. Dicha fase supuso un momento de impulso a las decadentes ciudades antiguas, hasta el punto que las no ocupadas, como Urci o Tarragona, desaparecerán. Pero el intento era artificioso y, pese a sus deseos, los obispos posiblemente no controlaban ya la red parroquial, desarticulada por iglesias propias, monjes autónomos y huida de la población al saltus. Es por ello por lo que se impondrá la segunda fase, donde los grandes linajes muladíes, controladores de los medios rurales, sustituyen a obispos y gobernadores árabes tanto en la Marca Superior como en el Suroeste peninsular. En la zona andaluza ese papel se le concederá a los ŷundíes, curiosamente con el mismo tercio de los amwal de los cristianos ${ }^{95}$ que habían alcanzado los obispos. La nueva fórmula se adecuaba mejor a la realidad del s. VIII, pero aún así suponía excesivas concesiones para un Estado. Las reformas de 'Abd al-Raḥmān II serán el inicio de la recuperación, realmente dificultosa, como lo demuestra el agitado s. IX.

\footnotetext{
${ }^{91}$ "El paso de Septimania", 47.

92 "El procés de formación, t. I, 7.

${ }_{93}$ "La institució comtal carolíngia», 70.

${ }^{94}$ "L'influence wisigothique", 74.

${ }^{95}$ Sobre su discusión, Manzano Moreno, E., «El asentamiento y la organización”, 330-338.
} 


\section{RESUMEN}

En el artículo se plantea el modo de poblamiento del s. VIII en al-Andalus, sobre el cual se defiende la existencia de dos esquemas sucesivos. En el primero de ellos se advierte el asentamiento de la población conquistadora en las antiguas sedes episcopales donde se situarán gobernadores árabes, y asimismo en un tipo de poblamiento intercalar, que suele recibir el nombre de qilä, y que ha dejado su rastro en la toponimia. Ese esquema originario se verá transformado hacia la mitad del siglo, al sustituirse la alianza 'āmilobispo en las ciudades por un mayor protagonismo de los medios rurales; en éstos aparecen grandes linajes muladíes en la Marca Superior y en el SO, mientras que en la actual Andalucía esa función será llevada a cabo con la instalación de los ŷundíes sirios, también asentados en los medios rurales, donde comienzan a proliferar las alquerías.

\section{ABSTRACT}

The article looks into how eighth-century al-Andalus was populated, proposing two successive stages. In the first, the settling of the conquering population at the old episcopal seats where Arab rulers would establish themselves can be observed. At the same time an intercalated kind of population can also be noticed that is usually known as qilä, which can still be appreciated in the toponymy. This initial stage suffered a transformation toward the middle of the century when the 'amil-bishop alliance of the cities was substituted by a bigger leadership coming from the rural areas. Within these, important Muladi families in the Marca Superior and the South West emerged, whereas in what is now known as Andalucía that function would be carried out with the installation of Syrian jundis, also settled in the rural milieu, where small villages begin to proliferate. 